\title{
Characteristic evaluation of corrosion of aluminum-based rigid conductor line
}

\author{
S. Mohri \& Y. Sato \\ Railway Technical Research Institute, Japan
}

\begin{abstract}
Aluminum-based rigid conductor lines have been widely used for tunnel sections due to a cost-saving factor and their lightweight structure. Aluminum, however, is easily corroded, and it is therefore important to understand the corrosive characteristics of aluminum under the practical environment. The corrosion of the conductor lines inside the tunnel section is mainly due to groundwater seepage, containing alkali components or seawater. The authors carried out an accelerated corrosion test with an aqueous solution of sodium hydroxide to comprehend the corrosive characteristics with alkali components. Another problem is a corrosion that is likely to occur at areas where different materials contact each other. The authors also carried out saltwater spraying tests for the contact area of aluminum-base and bronze contact wire with various corrosion resistances to investigate the corrosion caused thereby. The results of these tests are described elsewhere in this paper, and the authors have indicated the predicted lifetime of aluminium-based conductor lines under the various environments.
\end{abstract}

Keywords: corrosion, rigid conductor line, aluminum, tunnel section, water seepage.

\section{Introduction}

Rigid conductor lines have been widely provided with tunnel sections or subway systems because the height of power collection equipment can be lowered. Aluminium-based rigid conductor is especially effective for power collection quality due to its lightweight structure. Aluminium however easily corroded [1], it is therefore important to understand the corrosive characteristics 
of aluminium under the existing environment. The authors have carried out corrosion tests under various conditions, and predicted the lifetime of conductor lines. The results of these investigations are described elsewhere in this paper.

\section{Characteristics of corrosion of aluminum base}

\subsection{Outlines of aluminum corrosion}

The corrosion of aluminum is classified into uniform corrosion, galvanic corrosion and local corrosion. The aluminum is covered with oxide layer in the air. The uniform corrosion occurred when the layer is worn out. The layer is easily dissolved for the water whose $\mathrm{pH}$ is less than 4 (acid) or more than 8.5 (alkali) [2]. The galvanic corrosion is observed at areas where different metals contact [3]. The corrosion occurs according to the galvanic potential of the metals. The aluminum easily corroded because the potential of aluminum is less noble than that of copper, steel and other metallic materials. The local corrosion derived by the adhered ions, chloride, or sulfide for example. These ions cause pitting or filiform corrosion.

\subsection{Characteristics of corrosion under the practical environment}

Fig. 1 shows the cross section of aluminum-based rigid conductor line. Main aspects of the corrosion of the conductor line installed in tunnel sections are as follows:

(a) The uniform corrosion due to groundwater seepage containing alkali components

(b) The galvanic corrosion due to the contact between aluminum-base and bronze contact wire

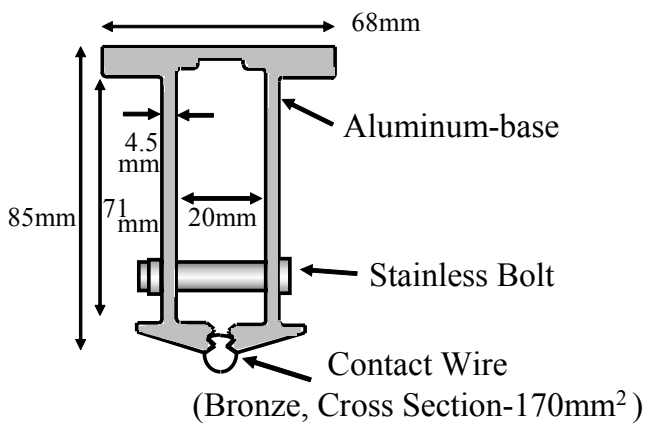

Figure 1: The Cross Section of Aluminum-based Rigid Conductor Line (Length of specimen for the test: $100 \mathrm{~mm}$ ).

\subsection{The tests for evaluating of corrosion}

For evaluating these corrosions, the authors carried out corrosion tests as follows: 
(a) Accelerated corrosion test by aqueous solution of sodium hydroxide was carried out for the investigation of the corrosion caused by alkaline water. The authors examined corrosion state and carried out tensile test of specimens.

Section 3.1 has described the results.

(b) The authors carried out tests to evaluate the effects of measure for galvanic corrosion. For example, tin-plating, anodic oxide layer and insulating of the contact area.

Section 3.2 has described the results.

(c) The authors carried out a saltwater spraying test to estimate the speed of corrosion at areas where aluminum-base and bronze wire contact with various corrosion resistances.

Section 3.3 has described the results.

\section{Tests results}

\subsection{The corrosion tests with alkali water}

\subsubsection{The outline of the tests}

Fig. 1 shows the aluminium-based rigid conductor lines immersed into aqueous solution of sodium hydroxide. The $\mathrm{pH}$ of the aqueous solution was 13 . For a comparison with the test specimen, hard-drawn aluminum stranded conductors, whose cross section of $200 \mathrm{~mm}^{2}$ was immersed together. The authors also carried out material fatigue tests after the specimens exposed for 123 hours.

\subsubsection{The results of the tests}

Prior to the evaluation of corrosion of the aluminum base, the authors measured the remains of aluminum in the stranded conductors by the eddy current wire diagnosis device as developed by our Institute. In comparison with the results of the conductors as installed in the existing railway system, it is possible to estimate corresponding test time to the existing system. Table 1 shows the summarized results. From the results, 123 hours under the test environment corresponds to 57 years under the practical environment.

Table 1: The comparisons of test hours with years under the practical environment.

\begin{tabular}{|c|c|c|c|}
\hline Specimen & $\begin{array}{c}\text { Test Hours } \\
(\mathrm{h})\end{array}$ & $\begin{array}{c}\text { Remains of } \\
\text { Aluminum (\%) }\end{array}$ & $\begin{array}{c}\text { Estimated Years } \\
\text { under the Practical } \\
\text { Environment (y) }\end{array}$ \\
\hline NEW & 0.0 & 100 & 0.0 \\
\hline A & 36.5 & 84 & 12.0 \\
\hline B & 53.0 & 74 & 19.7 \\
\hline C & 58.7 & 58 & 32.6 \\
\hline D & 123.3 & 26 & 57.4 \\
\hline
\end{tabular}


Table 2 shows the corrosion state of the specimens as classified in Table 1. The mass of the specimen D reduced by $14.1 \%$ in comparison with the specimen before exposed. The electric conductivities and modulus of elasticity are almost equal to the new specimen. The results indicate that the material properties themselves did not vary after the test completed.

Table 2: $\quad$ The corrosion state of the specimens.

\begin{tabular}{|c|c|c|c|c|}
\hline Specimen & $\begin{array}{c}\text { Mass of } \\
\text { Unit Length } \\
(\mathrm{kg} / \mathrm{m})\end{array}$ & $\begin{array}{c}\text { Mass } \\
\text { Reduction } \\
\text { Rate }(\%)\end{array}$ & $\begin{array}{c}\text { Electric } \\
\text { Conductivity } \\
(\%)\end{array}$ & $\begin{array}{c}\text { Module of } \\
\text { Elasticity } \\
(\mathrm{GPa})\end{array}$ \\
\hline NEW & 3.10 & - & 56.4 & 66.9 \\
\hline $\mathrm{A}$ & 2.93 & 5.5 & 57.0 & 65.8 \\
\hline $\mathrm{B}$ & 2.87 & 7.5 & 56.9 & 66.7 \\
\hline $\mathrm{C}$ & 2.79 & 10.1 & 56.7 & 66.4 \\
\hline $\mathrm{D}$ & 2.66 & 14.1 & 55.9 & 66.9 \\
\hline
\end{tabular}

Table 3 shows tensile test results. The fracture strengths of the specimen reduced according to hours exposed. The tensile strengths however, hardly varied because the thickness of cross sections also reduced. Under the installed condition, the stresses for the aluminum base mainly caused by the weight of the aluminum base itself and contact wire. Therefore, the specimen D has a sufficient strength usable for the existing system. It means the aluminum base is available in terms of the strength for 57 years in practical application with no problem.

Table 3: $\quad$ The results of tensile test.

\begin{tabular}{|c|c|c|c|c|}
\hline Specimen & $\begin{array}{c}\text { Cross Section } \\
\left(\mathrm{mm}^{2}\right)\end{array}$ & $\begin{array}{c}\text { Thickness of } \\
\text { Cross Section } \\
(\mathrm{mm})\end{array}$ & $\begin{array}{c}\text { Fracture } \\
\text { Strength (N) }\end{array}$ & $\begin{array}{c}\text { Tensile } \\
\text { Strength } \\
(\mathrm{MPa})\end{array}$ \\
\hline NEW & 110.1 & 4.50 & 25795 & 234 \\
\hline A & 100.9 & 4.23 & 23108 & 229 \\
\hline B & 98.3 & 3.88 & 22375 & 228 \\
\hline C & 93.4 & 3.77 & 21105 & 226 \\
\hline D & 48.6 & 1.95 & 11968 & 246 \\
\hline
\end{tabular}

\subsection{The evaluation of measures for galvanic corrosion}

\subsubsection{The outline of the tests}

The authors spayed saltwater to the specimens to evaluate the measures for galvanic corrosion as shown in Fig. 1, and measured the mass reductions of the specimens. The density of the saltwater was adjusted to $5.0 \%$, and the temperature was to 50 degrees centigrade. Table 4 indicates the measures for the specimens [4]. 


\subsubsection{The results of the tests}

The mass reductions of the aluminum base throughout the test reached to 100 days as shown in Fig. 2. The specimen of the largest mass reduction is specimen $\mathrm{A}$, and those of the smallest are specimen $\mathrm{D}$ and $\mathrm{E}$. The results indicated that the most effective measures for galvanic corrosion are anodic oxidation and the insulation of contact area. Plating metals also have some effect [5]. The authors also carried out a grip test as shown in Fig. 3. The max gripping force between the aluminum base and the contact wire were obtained as shown in Fig. 4. The results indicate that the all specimen satisfied the specified value $(5500 \mathrm{~N})$ for gripping the contact wire.

\subsubsection{The conclusions of the evaluation}

The most effective measures against the galvanic corrosion are to insulate contact wire or oxidize the aluminium base. These measures however are unsuitable to reduce the circulation current, because keeping the base and the wire to the same electric potential is the most effective to reduce the current. Plating should be paid attention in view of both suppressing the corrosion and reducing the circulation current; therefore, the authors decided to adopt tinning to the existing system. Furthermore, all the specimens have a sufficient strength to grip contact wire until the test reached to 100 days. The largest amount of mass reduction for 100 days is $5.2 \mathrm{~g}$ as shown in Fig. 2 (specimen A at 100 days). Therefore, the authors assumed that the mass reduction of $5.2 \mathrm{~g}$ is the limitation for use in the existing system.

Table 4: The measures of the specimens.

\begin{tabular}{|c|c|c|c|c|c|}
\hline Measure & $\mathrm{A}$ & $\mathrm{B}$ & $\mathrm{C}$ & $\mathrm{D}$ & $\mathrm{E}$ \\
\hline $\begin{array}{c}\text { Contact wire } \\
\text { (Bronze) }\end{array}$ & - & $\begin{array}{c}\text { Tin } \\
\text { - Plating }\end{array}$ & $\begin{array}{c}\text { Zinc } \\
\text { - Plating }\end{array}$ & - & - \\
\hline $\begin{array}{c}\text { Base } \\
\text { (Aluminum) }\end{array}$ & - & 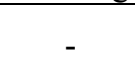 & 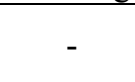 & $\begin{array}{l}\text { Anodic } \\
\text { Oxidation }\end{array}$ & Insulated \\
\hline
\end{tabular}

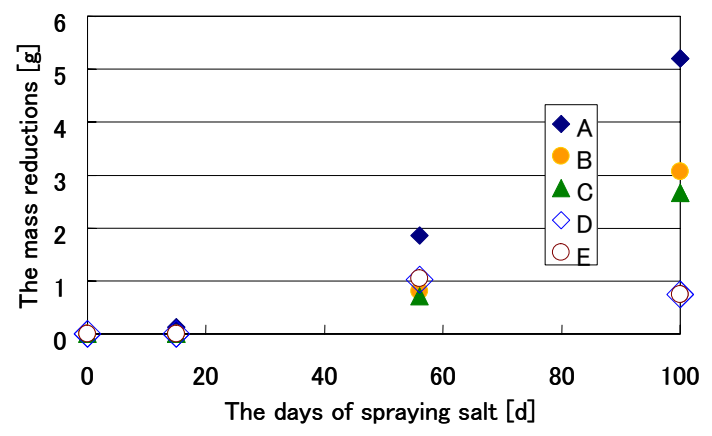

Figure 2: The mass reductions of the specimens. 


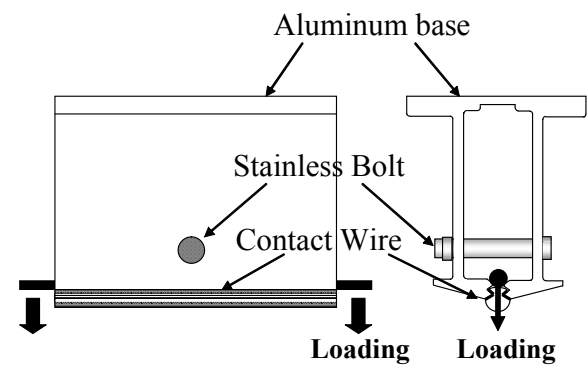

Figure 3: The outline of the grip test.

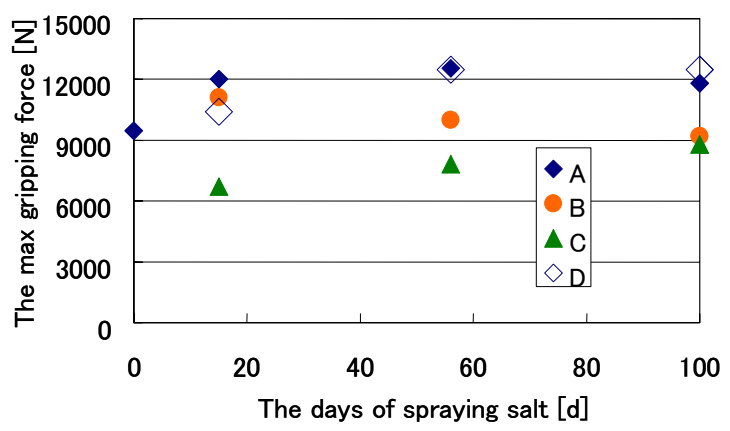

Figure 4: $\quad$ Max-gripping force between base and contact wire.

\subsection{The estimation for the speed of the galvanic corrosion}

\subsubsection{The outline of the whole tests}

The authors carried out to saltwater splaying tests to estimate the speed of the galvanic corrosion under the practical environment. The saltwater dropping tests, which simulated the practical environments, were also carried out. The authors decided the test conditions by the component analyses of groundwater seepage in tunnel sections. The mass reductions attempted to formulate by comparing the results of saltwater spraying test and dropping test.

\subsubsection{The outline of the saltwater spraying tests}

A cross section of contact wire will be reduced by wear. It will affect the corrosion speed. Another factor which affects the corrosion speed is diminishing of the plated tin. The authors carried out saltwater spraying test to investigate the effects of these factors to the corrosion speed. Fig. 1 shows the specimens and Table 5 shows the conditions of the contact wire. The density of the salt adjusted to $5 \%$, and the temperature adjusted to 50 degrees centigrade. The term of the test is up to 100 days. Fig 5 shows the mass reductions of the aluminum base. The result shows that the mass reduction speed of the aluminum base with the worn out wire is less than that of the new wire. The result also shows that the plated tin is suppressing the mass reduction. 
Table 5: The conditions of the contact wire.

\begin{tabular}{|c|c|c|c|c|}
\hline & (1) & (2) & (3) & (4) \\
\hline Plating & \multicolumn{2}{|c|}{ None } & Tin & $\begin{array}{c}\text { Tin -1/2 } \\
\text { diminished }\end{array}$ \\
\hline Cross Section & Normal & $\begin{array}{l}2 / 3 \\
\text { Cut }\end{array}$ & \multicolumn{2}{|c|}{ Normal } \\
\hline
\end{tabular}

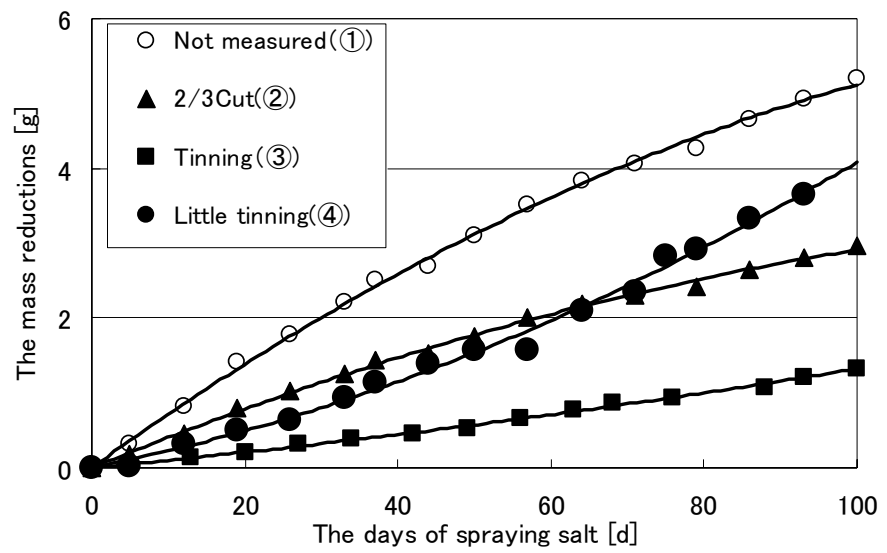

Figure 5: The mass reductions of the aluminum bases under the various conditions of contact wires.

\subsubsection{The outline of the saltwater dropping test}

To simulate the corrosion under the practical environment, the saltwater dropping test was carried out. The analyses of the groundwater seepage in tunnel, the conditions of the saltwater dropping were decided as shown in Table 6. The formulation of the speed of the mass reduction was made using the results of the saltwater dropping test. The reduction of the aluminum base can be formulated by exponential function (as $y=a e^{-b t}$ for the specimen 1 and 2 , as $y=a e^{b t}$ for the specimen 3 and 4). Table 7 shows the results of formulation.

Table 6: $\quad$ The conditions of the saltwater dropping tests.

\begin{tabular}{|c|c|c|c|c|}
\hline \multirow{2}{*}{$\begin{array}{c}\text { Conditions of } \\
\text { Water Seepage }\end{array}$} & \multicolumn{2}{|c|}{ Tunnel section near Sea } & \multicolumn{2}{c|}{ Tunnel Section near Mountain } \\
\cline { 2 - 5 } & Much Seepage & Little Seepage & Much seepage & Little Seepage \\
\hline \hline Densities & \multicolumn{2}{|c|}{$0.30 \% \mathrm{NaCl}$} & \multicolumn{2}{|c|}{$0.0025 \% \mathrm{NaCl}$} \\
\hline $\begin{array}{c}\text { Conditions of } \\
\text { Dropping }\end{array}$ & $\begin{array}{c}\text { Every } 10 \mathrm{sec} \\
0.1 \mathrm{ml}\end{array}$ & $\begin{array}{c}\text { Every } 60 \mathrm{sec} \\
0.1 \mathrm{ml}\end{array}$ & $\begin{array}{c}\text { Every } 10 \mathrm{sec} \\
0.1 \mathrm{ml}\end{array}$ & $\begin{array}{c}\text { Every } 60 \mathrm{sec} \\
0.1 \mathrm{ml}\end{array}$ \\
\hline
\end{tabular}


Table 7: The formulations of the speed of the corrosion.

\begin{tabular}{|c|c|c|c|c|}
\hline \multirow{2}{*}{ Specimen } & \multicolumn{2}{|c|}{ Tunnel Section near Sea } & \multicolumn{2}{c|}{ Tunnel Section near Mountain } \\
\cline { 2 - 5 } & $\begin{array}{c}\text { Much } \\
\text { Seepage }\end{array}$ & $\begin{array}{c}\text { Little } \\
\text { Seepage }\end{array}$ & $\begin{array}{c}\text { Much } \\
\text { Seepage }\end{array}$ & $\begin{array}{c}\text { Little } \\
\text { Seepage }\end{array}$ \\
\hline \multirow{2}{*}{1} & $a=3.7 \times 10^{-3}$ & $a=3.2 \times 10^{-3}$ & $a=1.1 \times 10^{-3}$ & $a=5.0 \times 10^{-4}$ \\
& $b=2.0 \times 10^{-4}$ & $b=2.0 \times 10^{-4}$ & $b=6.0 \times 10^{-4}$ & $b=3.0 \times 10^{-4}$ \\
\hline \multirow{2}{*}{2} & $a=2.1 \times 10^{-3}$ & $a=1.8 \times 10^{-3}$ & $a=6.2 \times 10^{-4}$ & $a=2.8 \times 10^{-4}$ \\
& $b=2.0 \times 10^{-4}$ & $b=2.0 \times 10^{-4}$ & $b=6.0 \times 10^{-4}$ & $b=3.0 \times 10^{-4}$ \\
\hline \multirow{2}{*}{3} & $a=5.0 \times 10^{-4}$ & $a=4.0 \times 10^{-4}$ & $a=2.0 \times 10^{-4}$ & $a=7.0 \times 10^{-5}$ \\
& $b=2.0 \times 10^{-4}$ & $b=2.0 \times 10^{-4}$ & $b=6.0 \times 10^{-5}$ & $b=3.0 \times 10^{-5}$ \\
\hline \multirow{2}{*}{4} & $a=1.1 \times 10^{-3}$ & $a=9.0 \times 10^{-4}$ & $a=3.0 \times 10^{-4}$ & $a=2.0 \times 10^{-4}$ \\
& $b=2.0 \times 10^{-4}$ & $b=2.0 \times 10^{-4}$ & $b=7.0 \times 10^{-5}$ & $b=3.0 \times 10^{-5}$ \\
\hline
\end{tabular}

Specimen 1 and 2

$$
y=a e^{-b t}
$$

Specimen 3 and 4

$$
y=a e^{b t}
$$

$y$ : the Speed of Mass

Reduction (g/d)

$t$ : the Days in Use (d)

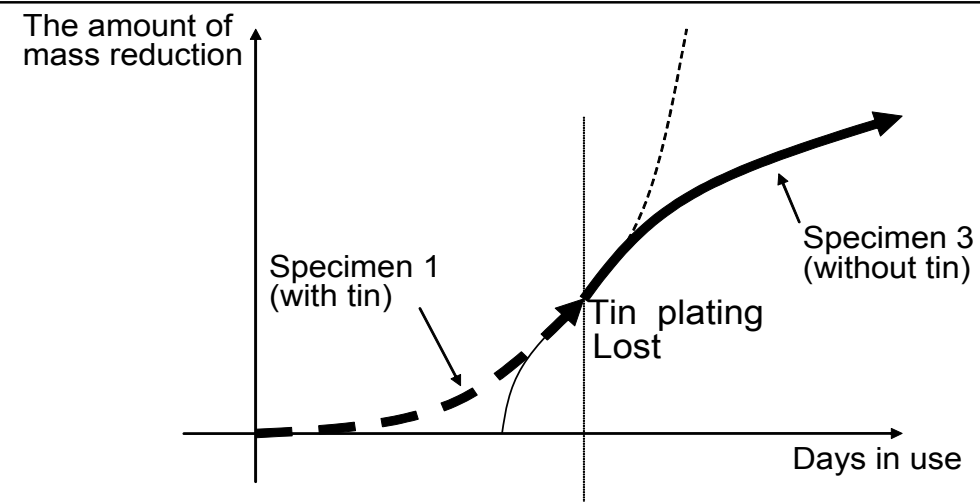

The speeds of mass reductions are coincided.

Figure 6: The way to calculate the term.

Table 8: $\quad$ The terms for the lost of plated tin.

\begin{tabular}{|c|c|c|c|c|}
\hline Conditions of & \multicolumn{2}{|c|}{ Tunnel section near Sea } & \multicolumn{2}{c|}{ Tunnel Section near Mountain } \\
\cline { 2 - 5 } Water Seepage & Much Seepage & Little Seepage & Much Seepage & Little Seepage \\
\hline Years & 8.3 & 8.7 & 27.4 & 41.9 \\
\hline
\end{tabular}

\subsubsection{The prediction of the lifetime of the aluminum base}

The plated tin will diminish gradually, so it is important to take into account of the effect of diminishing of plated tin for predicting the lifetime of aluminum base. The term for which the plated tin is lost is calculated in comparison with the specimen 1 and 3 indicated in Table 7. Fig. 6 shows the way of formulation about the term, and Table 8 shows the assumed terms.

On the other hand, the formulation of the mass reduction of the aluminum base was carried out. The factor $a$ in the speed of the mass reduction (formulated as $y=a e^{-b t}$ ) is approximated from the results of specimen 1 (new specimen) and 2 (cut specimen) shown in Table 7. The factor $a$ is also affected by diameter of contact wire. It is expressed as a linear function of used years. Fig. 7 shows the conditions of the formulation. 
The calculations of the amount of the mass reductions are carried out from the investigations mentioned above. Fig. 8 shows the procedure of the calculations, and Fig. 9 shows the results of calculations of the mass reductions. As mentioned in Section 3.2.3, the mechanical strength for use of the aluminum base is guaranteed until the mass reduction reached to $5.2 \mathrm{~g}$, and the authors assumed that this term is a lifetime of the aluminum base. Table 9 shows the predicted lifetimes of aluminum bases as obtained from Fig. 9.

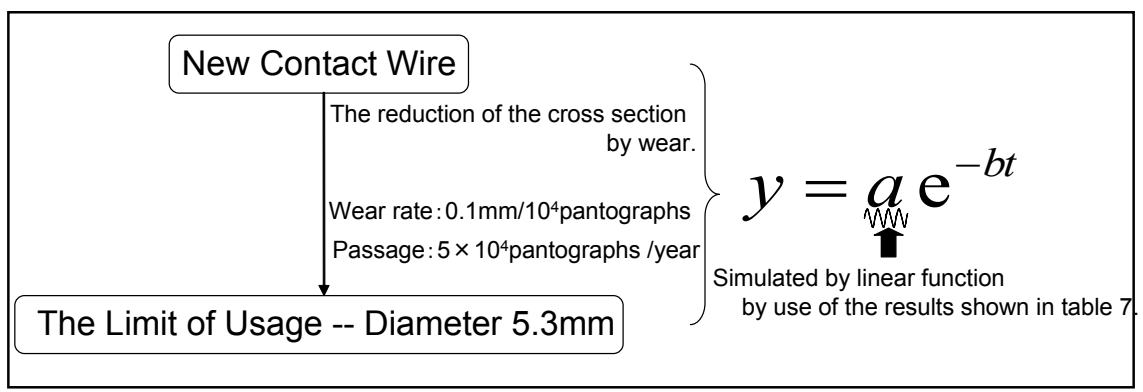

Figure 7: The conditions of the formulation.

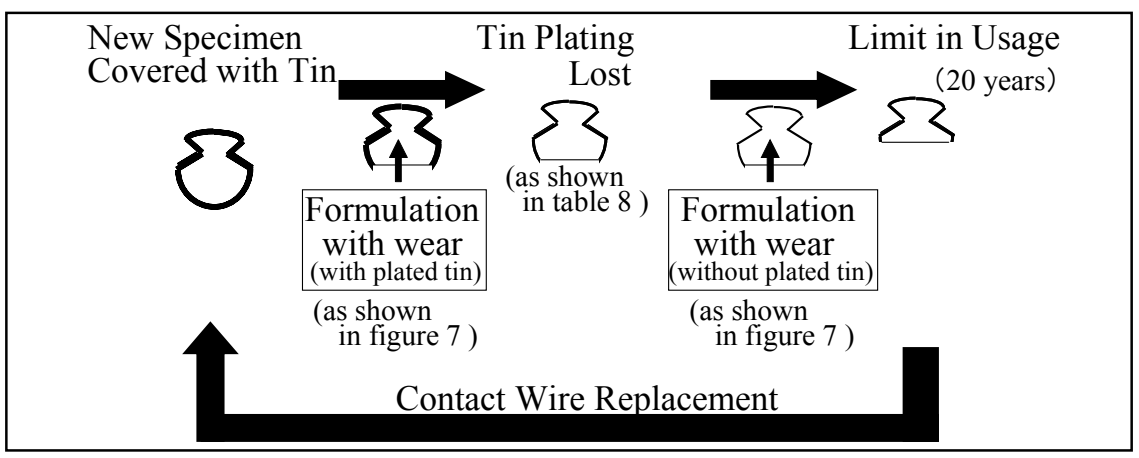

Figure 8: The procedure of the calculations of the mass reduction.

\section{Conclusions}

The authors carried out corrosion tests of the aluminum-based rigid conductor lines. The authors took into account two aspects of corrosion. One is caused by ground water seepage which contains the alkali materials. The other is galvanic corrosion at the contact area of the aluminum base and the contact wire. The conclusions of this paper are as follows:

(1) The material characteristics, such as tensile strength and others did not vary throughout the accelerated corrosion test with aqueous solution of sodium hydroxide. The test term was corresponded to 57 years in practical environment. The results mean that the aluminum base has no problem for strength until 57 years in use. 


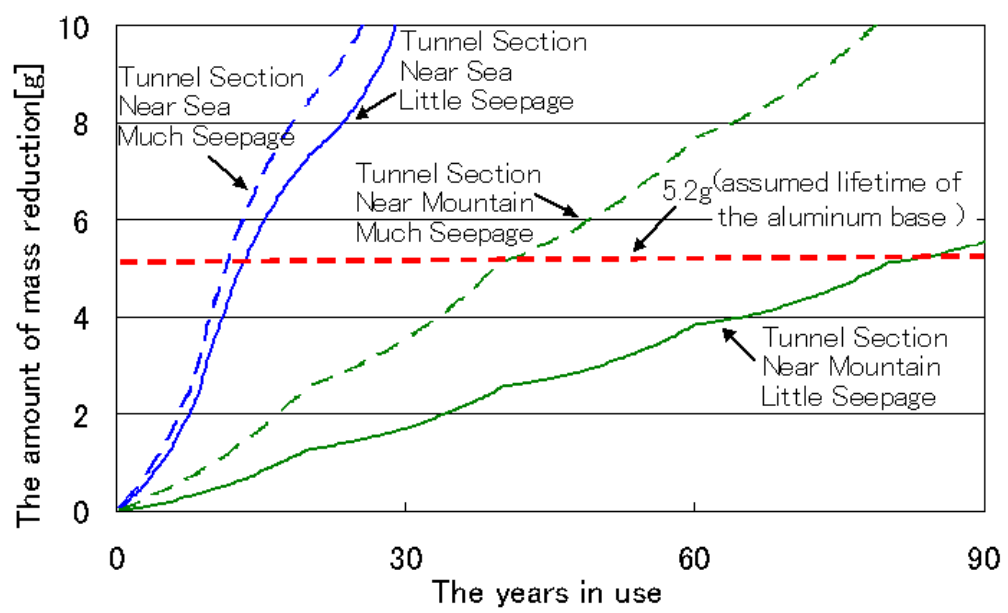

Figure 9: The amount of the mass reduction of aluminum base (calculated).

Table 9: $\quad$ The predicted lifetimes of aluminum bases.

\begin{tabular}{|c|c|c|c|c|}
\hline \multirow{2}{*}{$\begin{array}{c}\text { Conditions } \\
\text { of Seepage }\end{array}$} & \multicolumn{2}{|c|}{ Tunnel section near Sea } & \multicolumn{2}{c|}{ Tunnel Section near Mountain } \\
\cline { 2 - 5 } & Much Seepage & Little Seepage & Much Seepage & Little Seepage \\
\hline Lifetime (y) & 11 & 13 & 40 & 80 \\
\hline
\end{tabular}

(2) The most effective measure for the galvanic corrosion was to insulate contact wire or oxidize the aluminium base. The plating, however, was also effective in both suppressing the corrosion and reducing the circulation of current.

(3) The aluminum base, whose mass reduction reached to $5.2 \mathrm{~g}$, had a sufficient strength to grip the contact wire. This amount of the mass reduction was conceivable as the limitation for use in the existing system.

(4) The predicted lifetime of aluminum base with tin plated contact wire is from 11 to 13 years in the tunnel section near seashores, and from 40 to 80 years near mountainous areas.

\section{References}

[1] Samuel, L.C. \& Kent, R.V.H., Aluminum in Iron and Steel, John Wiley \& sons, Chapman \& Hall: New York and London, pp.82 83, 1953.

[2] Wilson, C.L. \& Oates, J.A., Corrosion and the Maintenance engineer, Hart Publishing Company: New York, pp. 68 69, 1968.

[3] Boris, H.T., Isidore, G. \& Herman S.P., Theory of Corrosion and Protection of Metals, Macmillan Company \& Collier-Macmillan limited: New York and London, pp. 165 193, 1966.

[4] Schmidt, D.P., Shaw B.A., Sikora, E. \& Shaw, W.W., Corrosion Protection Assessment of Barrier Properties of Several Zinc-Containing Coating Systems on Steel in Artificial Seawater, Corrosion, 62(4), pp.323 339, 2006.

[5] Johnson, C.M., Tyrode E. \& Leygraf, C., Atmospheric Corrosion of Zinc by Organic Constituents, Journal of the Electrochemical Society, 153(3), pp. $113121,2006$. 